\title{
Comparative Study on Principal Leadership Effectiveness in Government and Private Secondary Schools of Hawassa City Administration
}

\author{
SOLOMON LEMMA LODISSO \\ Associate Professor, Department of Educational Planning and Management, Hawassa University
}

\begin{abstract}
The purpose of this study was to compare principal leadership effectiveness between those working in government and private secondary schools of Hawassa City Administration. Comparative research design was used. Eight and four schools from government and private secondary schools respectively were selected purposively because the principals served for more than four years and teachers could judge their effectiveness. Using Yamane's (1967) formula, 280(150 from government and 130 from private schools) teachers made the sample. The sample was distributed across the eight schools proportionally. Participants were selected using simple random sampling techniques. A questionnaire was used to collect data. The study found a significant difference in effectiveness between government and private secondary school principals for Government school principals. To maintain and/or enhance the overall school effectiveness, it is recommended that principals should be supported by all the constituents, particularly teachers and the community.
\end{abstract}

Keywords: comparative study, government secondary schools, principal's leadership effectiveness, Private secondary schools

DOI: $10.7176 / \mathrm{JEP} / 10-28-07$

Publication date:October $31^{\text {st }} 2019$

\section{INTRODUCTION}

Organizational success depends mostly on the effectiveness of leaders (Popa 2012). In context of school, the term effectiveness can be defined as ability of a principal to work with or through people to achieve the mission and vision of the school in a manner that brings about continuous improvement (Alabi \& Alabi 2014). In line with this, Houston and Dockstader (2002), Alabi and Alabi (2010) conceptualized effective leadership as the ability to achieve a vision and continuously improve the human, economic and social capital of the organization in a sustainable manner. In defining effective leadership, Montgomery (2005) stressed the visibility of the leader and nine other elements which include need for a two-way trust, teamwork, clear objectives, equally clear communication, self-belief, back-up with adequate resources, insistence on good performance, humility, and controlled aggression towards the opposition. From his perspective, an effective leader has to articulate a vision and communicate that vision clearly to members and stakeholders to buy into it.

Since successful organizations are the result of effective leadership (Popa, 2012), Leithwood, (1999) states that effective school leadership is crucial for the success of a schools or school systems. In particular, principal's efficiency and competence are crucial for the success of any school system. Research has shown that one of the major causes of failure for organization would be ineffective leadership and poor implementation of educational programs (Harris, 2003). Thus, principal's effectiveness is the positive response to school leader efforts and actions with the intention of accomplishing stated goal.

It known that without effective principal at all levels in private and government schools, it is virtually impossible to achieve and to sustain effective administration. According to Sheninger (2011), the increasing complexity and requirements arising from the context of change in society, coupled with the constant push for higher levels of productivity, requires effective and ethical leadership. He further stated that effective leadership is essential requirement for any organization to be considered successful in by all stakeholders in the $21^{\text {st }}$ century.

Research on leaders' effectiveness has identified a number of variables that differentiate effective from noneffective leaders. For instance, Smith and Andrew (1999), reported that characteristics of strong effective school leaders include commitment to the goals of school, ability to gather and mobilize resources to accomplish goals, team building and promoting ,ability to monitor students' progress towards school achievement and teacher effectiveness in meeting goals, ability to define school mission, promote positive learning climate, observe and give feed-back to teachers and manage and access the curriculum and the instructional program. On the other hand, Popa (2012), explained effective leader as value-oriented, creative, intellectually driven and knowledgeable, selfconfident, ethical, foster participation in school decision making, and charismatic. He goes on to say that an effective leader has the vision, dedication, integrity, and is creative and open towards new approaches and people, ensures that credit for success is given to all employees and at the same time he will take responsibility for failures. Alabi \& Alabi (2014) identified five core themes for effective leaders and these include personal competences, visionary competences, administrative competences, people competences and networking competences. 
The indicators of effective school leaders according to Kouzes and Posner (2002) are as follows; strategic thinkers, role models, decision makers, mentors, mediators, consensus seekers or builders, self-evaluators, team creators and promoters, fair and balanced, good communicators, lead through influence and example setting, takers and givers of feedback, emphatic listeners, walking the talk, visionary, have service mentality and technical or contextual expertise. Even though, a number of variables were identified in the literature, this research compared principals effectiveness in private and government school using the following variables that were identified by Smith and Andrew (1999), Kouzes and Posner (2002) and Popa (2012) which make a lealdler effective. These variables are: Effectiveness in organizational planning and goal setting (visionary), foster participation in school decision making, monitor students progress, team building and promoting, and good communicator. These variables were also stated in school improvement program document as a role of school principal (see MoE, 2011a) so that these are crucial to assess the effectiveness of school principals. Even though there are other variables included in the document this study delimited to these roles in order to compare the two schools.

\section{The Education System in Ethiopia}

The education system in Ethiopia as currently structured, consists of the first primary cycle (grades 1-4), Second primary cycle (grades 5-8), Lower secondary cycle (grades 9-10) Preparatory school cycle (grades 11-12), Technical and vocational education and training (TVET) $(10+1,10+2$ and 10+3), Higher education (institutions that provide undergraduate and postgraduate programs (Federal Democratic Republic of Ethiopia (FDRE). 2002). The preprimary level created for children aged 4-6 years and is dominated by privately run institutions, with only few per cent of students at this level attending government schools (MoE, Education Statistics 2009). However, by the time children enter the primary level (age 7-13 years), over 80 per cent are enrolled in government institutions and the same is true for secondary schools. Secondary schools in this research refer to lower secondary cycle (grades 9-10). In Ethiopia private schools are independent schools, which are established by nongovernmental agencies and individuals, for profit making venture while government schools were established by government, which are free from payment and opened to all members of the society.

Currently, observations show many Ethiopia families who can particularly prefer to send their children to private schools. It is believed that teachers in private schools show much dedication and appear to perform better on their job compared to those in Government. This has been attributed to the deplorable conditions in government schools (Solomon, 2019). The poor quality of teaching and learning process in government schools has led many parents to choose private schools. It is also believed by parents that private schools in Ethiopia are more efficient and effective. Teshome (2017) in his findings reported a number of reasons why parents prefer private school as that learning in private schools leads to more academic achievements than in public schools, private schools make rigorous selection of students, admitting students with appropriate age from families having higher levels of education and private schools provide more access to classrooms and teachers, attractive work environment, sufficient facilities, qualified teachers, enriched curricula and focused on results.

All the secondary schools in Ethiopia follow the same curriculum set by the Ministry of Education, but the academic achievement of students from private schools have been better than that of the government schools. This is likely the reason people think private schools are better than government schools even though teachers in Government schools are believed to be better paid and more qualified and schools have better facilities. In Hawassa City Administration, it is assumed by general public that principals in private schools are more effective on their job and they handle the staff effectively and make them produce good results. It is observed that although public schools seem to have more qualified teachers and principals have relatively better facilities, nevertheless, they did not attract much patronage especially from the elite, rich and even the government workers.

Thus, this research assessed the differences in effectiveness of leadership between principals working in Government and those working in private school through the following research questions. 1) Are the perceptions on teachers about principals' leadership effectiveness in both government and private general secondary schools? 2) Which factors of effectiveness predict principal leadership effectiveness in government and private secondary schools?

The capabilities of school leaders vary greatly, and some are more effective than others. One way to analyze the effectiveness of school principals is to simply ask members of their organizations for perceptual ratings (Johnson, 2006). The position(s) of respondents in organizations and their access to important evaluative information, especially teachers, gives them insights into organizational effectiveness in relation to leadership (Johnson 2006). For this reason, this study used teachers' responses as a source of data to assess the effectiveness of the principals.

\section{METHODS AND MATERIALS}

In this study, comparative research design was used to respond to the research questions. Eight schools (four from government and four from private) secondary schools were selected purposively. The principals in these schools had served for more than four years, a period long enough for that teacher to able to judge their effectiveness. 
Using Yamane's (1967) formula 280 (150 from government and 130 from private) teachers made the sample from the two groups). The sample was distributed to the eight schools proportionally. All participants from each school were selected using simple random sampling techniques. The questionnaire, developed by the researcher was used to collect data after pilot survey. Pilot test was conducted to check validity and reliability. The respondents were asked to rate their principals using a five-point scale (very high $5=$, high $=4$, medium $=3$, low $=2$, and very low $=1)$. Data were analyzed using descriptive as well as inferential statistical measures. The mean value of each item in the tables indicates the average mean values of the items under each variable (item). For example, organizational planning and goal setting item has four different questions related to it. The mean value thus indicate the average of all the four items. The same is true for the rest four items.

\section{RESULT OF THE STUDY}

The sample profile of the participants indicates that the average age of the sample was 31.6 years. From the total participants, $63.6 \%$ were male and $36.4 \%$ were females. In terms of educational status $89.7 \%$ had first degree while the rest $10.3 \%$ were second degree holders. Participants from government, on an average, had 10.6 years of experience and from private schools on average had 4.6 years of experience. Table 1 below shows the result of mean value and $t$-test results used in comparing the effectiveness of principals in the two groups of schools. Table 1: Perception of teachers on school principal's effectiveness

\begin{tabular}{|c|c|c|c|c|c|c|}
\hline No. & items & respondents & mean & s.d & t-value & P-value \\
\hline \multirow[t]{2}{*}{1} & \multirow[t]{2}{*}{ Organizational planning and goal setting } & Gov't & 3.51 & 1.14 & \multirow[t]{2}{*}{1.95} & \multirow[t]{2}{*}{.105} \\
\hline & & Private & 3.66 & 1.17 & & \\
\hline \multirow[t]{2}{*}{2} & \multirow{2}{*}{$\begin{array}{l}\text { Fostering participation in school decision } \\
\text { making }\end{array}$} & Gov’t & 3.20 & 1.37 & \multirow[t]{2}{*}{11.20} & \multirow[t]{2}{*}{.000} \\
\hline & & Private & 1.64 & 0.86 & & \\
\hline \multirow[t]{2}{*}{3} & \multirow[t]{2}{*}{ Monitoring students' progress } & govt & 1.82 & 1.09 & \multirow[t]{2}{*}{-11.29} & \multirow[t]{2}{*}{.000} \\
\hline & & Private & 3.46 & 1.35 & & \\
\hline \multirow[t]{2}{*}{4} & \multirow[t]{2}{*}{ Team building and promoting } & govt & 3.87 & 1.01 & \multirow[t]{2}{*}{6.22} & \multirow[t]{2}{*}{.000} \\
\hline & & Private & 2.99 & 1.35 & & \\
\hline \multirow[t]{2}{*}{5} & \multirow[t]{2}{*}{ Good communication } & Gov't & 3.91 & 1.18 & \multirow[t]{2}{*}{14.97} & \multirow[t]{2}{*}{.000} \\
\hline & & Private & 1.91 & 1.03 & & \\
\hline
\end{tabular}

*Mean value $<1.5$ is low $1.56-3.00$ medium and $>3.01$ considered as high

Leadership effectiveness depends on multiple constituencies. This study examined whether there exists significance differences in the effectiveness of school leadership between Government and private schools on the variables on leadership effectiveness (organizational planning and goal setting, level of participation in decision making, monitoring students' progress, team building and good communication skills) as perceived by the teachers.

With regard to the first item, teachers in both government and private secondary schools perceive their principals as highly effective with the mean value of 3.51 and 3.66 respectively. In relation of teachers' participation in decision making, government school principals were more effective than the private school principals. This was reported by the mean value of 3.20 and 1.64 for government and private schools respectively. For the third item, it was reported by private school teachers that their principals are highly effective with mean value of 3.46 and government school teachers rated their principal as very low with the mean value of 1.82.

In relation to the fourth and the fifth items (team building and promoting and good communicator), teachers in government and private schools perceive their principals differently. For both items, principals in private schools were perceived as less effective than government school principals (See Table 1).

Regression analysis was done to identify the most important predictor variable(s) for principals effectiveness in secondary schools of Hawassa City Administration. Table 2a and $2 b$ depicts the result of the regression between perceived control of independent variables (factors that determine leadership effectiveness) and dependent variable (principals' effectiveness). Preliminary analyses were performed for the two groups of data to ensure no violation of the assumption of normality, linearity and homoscedasticity.

Table 2a Model summary for government secondary school

\begin{tabular}{|l|l|l|l|l|}
\hline Model 1 & $\mathrm{R}$ & $\mathrm{R}$ square & Adjusted R square & $\begin{array}{l}\text { Std. Error of the } \\
\text { Estimate }\end{array}$ \\
\hline 1 & $.232^{\mathrm{a}}$ & .051 & .021 & 1.340 \\
\hline
\end{tabular}

a. Dependent Variable: Principals' effectiveness inventory

b. Predictors: (Constant), good communicator, Team building and promoting, Organizational planning and goal setting, fostering participation in school decision making, Monitoring students progress

The model summary in Table $2 \mathrm{a}$ indicates how much of the total variance in the dependent variable is uniquely explained by that variable and how much R square would drop if it wasn't included in the model. From the Table $2 \mathrm{a}$ the independent variables in the government schools' data have a partial coefficient of .232. If we square this 
we get .054 , indicating that all the independent variables uniquely explain 5 percent of the variance in leadership effectiveness

Table 2b Model Summary b for private school data

\begin{tabular}{|l|l|l|l|l|l|}
\hline Model & $\mathrm{R}$ & R Square & $\begin{array}{l}\text { Adjusted } \\
\text { Square }\end{array}$ & Std. Error of the Estimate \\
\hline 1 & $.621 \mathrm{a}$ & .385 & .360 & 1.070 \\
\hline
\end{tabular}

a Predictors: (Constant), good communicator , Organizational planning and goal setting, Team building and promoting, Fostering participation in school decision making, Monitoring students progress

b Dependent Variable: principals effectiveness inventory

Similarly, the model summary in Table $2 \mathrm{~b}$ reports how much of the total variance in the dependent variable is uniquely explained by that independent variables and how much R square would drop if it wasn't included in the model. From the Table $2 \mathrm{a}$ the independent variables in the private secondary schools data have a partial coefficient of .621. If we square this we get .385, indicating that all the independent variables uniquely explain 38 percent of the variance in leadership effectiveness.

The regression analysis in the following Table also indicated the contribution of each independent variable (in this case leadership role) when the other variables held constant.

Table 3a Coefficients for government secondary schools data

\begin{tabular}{|l|l|l|l|l|l|}
\hline \multirow{2}{*}{ Model } & \multicolumn{2}{l|}{$\begin{array}{l}\text { Un-standardized } \\
\text { Coefficients }\end{array}$} & $\begin{array}{l}\text { Standardized } \\
\text { Coefficients }\end{array}$ & T & Sig. \\
\cline { 2 - 6 } & \multicolumn{1}{|c|}{$\mathrm{B}$} & Std Error & \multicolumn{1}{|c|}{ Beta } & & \\
\hline (constant) & 2.765 & .670 & & 4.129 & .000 \\
\hline Organizational planning and goal setting & -.035 & .083 & -.034 & -.415 & .679 \\
\hline $\begin{array}{l}\text { Fostering participation in school decision } \\
\text { making }\end{array}$ & .050 & .081 & .051 & .618 & .537 \\
\hline Monitoring students progress & -.176 & .107 & -.141 & -1.637 & .104 \\
\hline Team building and promoting & .014 & .111 & .011 & .126 & .900 \\
\hline Good communication & .164 & .097 & .143 & 1.686 & .094 \\
\hline
\end{tabular}

Table $3 \mathrm{~b}$ Coefficients for private secondary schools data

\begin{tabular}{|c|c|c|c|c|c|}
\hline \multirow[t]{2}{*}{ Model } & \multicolumn{2}{|c|}{$\begin{array}{l}\text { Un-standardized } \\
\text { Coefficients }\end{array}$} & \multirow{2}{*}{$\begin{array}{l}\text { Standardized } \\
\text { Coefficients } \\
\text { Beta }\end{array}$} & \multirow[t]{2}{*}{$\mathrm{T}$} & \multirow[t]{2}{*}{ Sig. } \\
\hline & $\mathrm{B}$ & Std Error & & & \\
\hline (constant) & .379 & .537 & & .706 & .481 \\
\hline Organizational planning and goal setting & .690 & .082 & .603 & 8.406 & .000 \\
\hline Foster participation in school decision making & -.133 & .113 & -.085 & -1.171 & .244 \\
\hline Monitoring students progress & .018 & .072 & .019 & .255 & .799 \\
\hline Team building and promoting & .102 & .072 & .103 & 1.431 & .155 \\
\hline Good communication & .015 & .095 & .012 & .016 & .873 \\
\hline
\end{tabular}

Table $3 \mathrm{a}$ and $3 \mathrm{~b}$ help us to determine which of the variables included in the model contributed to the prediction of the dependent variable in both group of schools. The largest beta value in the government school is .143, which is for good communication. This shows that increasing effective communication makes the strongest unique contribution to explaining the principal effectiveness in Government schools when the variance explained by all other variables in the model is controlled for. The other variables are not making a significant unique contribution to the prediction of the dependent variable. This may be due to overlap with other independent variables in the model.

The private secondary schools' data indicated that the largest beta value is .603, which is for organizational planning and goal setting. This means that this variable makes the strongest unique contribution to explaining principal effectiveness, when the variance explained by all other variables in the model is controlled for. The beta value for good communication was slightly lower (.012), indicating that it made less of a contribution.

\section{DISCUSSION AND CONCLUSIONS}

The descriptive statistics, the mean value, indicated that principals in government schools are more effective with regard to organizational planning and goal setting, fostering participation in decision making, team building and team promoting and good communication. On the other hand, private secondary school leaders were also highly effective in organizational planning and goal setting, and monitoring students' progress. An independent $t$-test was conducted to compare each variable for government and private secondary schools. As it indicated there was no significant difference in organizational planning and goal setting score for government $(\bar{x}=3.64, \mathrm{SD}=1.14)$ and private, $\bar{x}=3.66, \mathrm{SD}=1.17 ; \mathrm{t}(230)=1.95, \mathrm{p}=.105$ (two-tailed). In all other variables 
there were significant differences between government and private secondary schools scores (see Table 1).

From the above presentation one can conclude that government school principals were reported to exhibit higher levels of effectiveness in three variables compared to private secondary school principals (fostering participation in school decision making, team building and communication). This shows that effective leader clearly communicates to staff about the work, solves problems and there is widely practiced co-teaching to transfer knowledge and instructional practices. This shows that government secondary school leaders were more effective than private school principals with respect to participation in school decision making, team building and communication.

On the other hand, private school principals were more effective than government schools in monitoring students' progress. The result may imply that in private school the use of data garnered from assessments and test as well as to drive instruction and teacher evaluation. It may indicate that in these schools, tests accommodate a range of entry points and teachers in private use extensive student data to determine instructional strategies and gaps in achievement are used to plan specific interventions. In addition to that the number of students per class in private schools was small compared to government, which is more than 70 students in class. As to the knowledge of the researcher in Ethiopia principals in private schools paid more than that of the government schools. That may matter a lot.

The result also indicated both groups of schools were more effective in organizational planning and goal setting. Since the two groups of schools were effective in planning and goal setting indicate that these schools set very ambitious performance targets and communicate these targets to the school community.

The key finding the study reported was that there is a significant difference between government and private secondary schools with government secondary school principals being more effective than private school principals in most of the variables. But in the actual situation in Hawassa City Administration private schools perform better than government secondary schools. It was reported that the contribution of the above mentioned variables were very small, about 5\%. This implies that this may be due to other factors other than principals' effectiveness, the recruitment of competent teachers, good pay for teachers, teaching and well-set control system, and good enrollment system. Thus, it is recommended that further study be needed to identify factors other than principals' effectiveness that attracts people to private schools.

There is growing evidence to suggest that leader's effectiveness is influenced by the perceptions and expectations of the subordinates (Williams, 2013). The results of this study show that if teacher's perceptions of their principals are effective in such areas as organizational planning and goal setting, decision making and communication skills and monitoring learning progress, the principals may be more likely to be effective. Therefore, in order to maintain and/or enhance the overall school effectiveness, principals understand and observe the variables that contribute to effectiveness. In addition to that they must get support from all the constituents, particularly from their teachers and the community.

\section{REFERENCES}

Alabi ,Goski\& Alabi,Joshua (2014). Understanding the Factors that Influence Leadership Effectiveness of Deans in Ghana, Journal of Higher Education in Africa, Vol. 12, No. 1

Alabi, J. \& Alabi, G., 2010, 'Factors Influencing Quality of Leadership in Higher Institutions of Learning in Ghana', Journal of Business Research Vol. 4, Nos. 1\&2,

Federal Democratic Republic of Ethiopia (FDRE). 2002. Education Sector Development Programme II (ESDP): Programme action plan. Addis Ababa: Ministry of education

Harris, Alma 2003. Teacher Leadership as Distributed Leadership: heresy, fantasy or possibility? School Leadership \& Management, Vol. 23, No. 3, pp. 313-324.

Kouzes, J. M., and Posner, B. Z., 2002, 'The Leadership Challenge: How to Get Extraordinary Things Done in Organizations, San Francisco: Jossey-Bass

Leithwood, K. (1990). The principals' role in teacher development. In B. Joyce (Ed.), Changing school culture through staff development. Alexandria, VA: Association of Supervision and Curriculum Development.

Ministry of Education (M.o.E.) (2011a). Governing guidelines for the implementation of the school improvement program (revised). Addis Ababa: M.o.E.

(2009).Education statistics annual abstract. Addis Ababa: Education sector development programme planning and analysis department

Solomon Bogale (2019). "The effect of principal's instructional leadership role on students' academic achievement in secondary schools of Sidama zone, Hawassa University", Unpublished M.A thesis

Popa, Brindusa Maria2012. The Relationship Between Leadership Effectiveness And Organizational Performance Journal of Defense Resources management, Vol 3 issue 1(4)

Smith and Andrew, (1999). Instructional Leadership: How principals make a difference? New York: Assanfor supervision and curriculum

Teshome Nekatibeb (2017). Public Schools and Private Schools in Ethiopia: Partners in National Development? 
International Journal of Humanities Social Sciences and Education (IJHSSE) Volume 4, Issue 2, PP 100111

Williams, Carol Watson (2013). School effectiveness in Jamaica: what do successful schools look like? Accessed on December 2018

Yamane, T. (1967). Statistics: an introductory analysis, $2^{\text {nd }}$ ed. New York: Harper and Row. 